Shachaf, P. (in press). Social Reference: A unifying theory. Library \& Information Science Research.

\title{
Social reference: Toward a unifying theory
}

\section{Pnina Shachaf}

School of Library and Information Science, Indiana University, 1320 E. 10th St., Bloomington, IN 47405-3907

Fax: +18128556166

E-mail address: shachaf@indiana.edu

\begin{abstract}
This article addresses the need for a theoretical approach to reference research and specifically concentrates on a lacuna in conceptual research on social reference. Social reference refers to online question answering services that are provided by communities of volunteers on question and answer (Q\&A) sites. Social reference is similar to library reference, but at the same time, it differs significantly from the traditional (and digital) dyadic reference encounter; it involves a collaborative group effort and uses wikis and other Web 2.0 infrastructure. This article proposes a sociotechnical framework to analyze, evaluate, and understand social reference that relies on a systems approach to the reference encounter, combined with an input-process-output (IPO) approach to virtual group work. The framework also accounts for the collaborative process of question answering and the interplay between technology and users, in their contexts.
\end{abstract}

\section{Introduction}

With the emergence of Web 2.0 and the rapid growth of participatory social sites, such as Flickr, YouTube, Wikipedia, and Yahoo! Answers, and with the advent of ideas from books such as The Wisdom of Crowds (Surowiecki, 2004), Here Comes Everybody (Shirky, 2008), and Everything is Miscellaneous (Weinberger, 2008), many traditional conceptions of information creation, dissemination, seeking, and use are being challenged. Taking advantage of the assumption that everyone knows something (Adamic, Zhang, Bakshy, \& Ackerman, 2008) and is willing to share knowledge, social Q\&A sites that process millions of information requests are flourishing, and crowd sourcing reference work. The number of visits to these sites increased by $889 \%$ in just two years (from 2006 to 2008), and by 118\% since 2007 (Hitwise, 2008). The three most frequently visited Q\&A sites in March 2008 were Yahoo! Answers, with 74\% of the market share of U.S. visits; WikiAnswers, with 18\%; and Answerbag, with 4\% (Hitwise, 2008). The largest among these sites, Yahoo! Answers, includes over 23 million resolved questions and over 100 million users (Adamic et al., 2008; Dom \& Paranjpe, 2008). Research on Q\&A sites is in its infancy; it has mostly focused on information retrieval (e.g., Agichtein, Castillo, Donato, Gionides, \& Mishne, 2008; Bian, Liu, Agichtein, \& 
Zha, 2008) and information seeking behavior (Oh, Oh, \& Shah, 2008; Gazan, 2007; Shah, Oh, \& Oh, 2008). Q\&A sites raise fundamental questions for information retrieval researchers, who are challenged to incorporate a social dimension into the retrieval mechanism, and for reference researchers, who are challenged to understand the nature of the collaborative reference encounter. Both are interested in identifying answers of high quality.

In an effort to distinguish between high and poor quality answers, researchers have focused attention on answer quality at various Q\&A sites (Adamic et al., 2008; Agichtein et al., 2008; Bian et al., 2008; Dom \& Paranjpe, 2008; Gazan, 2006, 2007 Harper, Raban, Rafaeli, \& Konstan, 2008; O'Neill, 2007; Shachaf, in press), and found that answer quality varies not only on each Q\&A site, but it also varies from one site to another (O'Neill, 2007; Harper et al., 2008); some of the Q\&A sites provide services that match or surpass library reference services (Harper et al., 2008; Shachaf, in press).

\section{Problem statement}

For reference research, online social reference exemplifies a new stage that involves a transition from a dyadic question negotiation to an online collaborative group effort; it goes beyond the simple use of technology. The rapid growth of these Q\&A sites have been enabled and facilitated by the deployment of Web 2.0 technologies (e.g., wiki) and mass user participation. Using the same features of Web 2.0, new business models, such as those of Google Answers and ChaCha, have been developed. As a result, questions about costs and benefits, economic viability and sustainability, answer quality, and service effectiveness are now more critical than ever and should be systematically addressed. In view of that, service effectiveness should be examined, quality measures should be clearly determined, and theoretical models should be identified, modified, and developed to explain, analyze, predict, and evaluate these Q\&A sites.

Specifically, there is a need to develop a conceptual framework to understand social reference and to facilitate the analysis and evaluation of social Q\&A sites. It is possible that this phenomenon has not yet been addressed from a theoretical angle because of the fact that social reference is a relatively new phenomenon that has been understudied (Shah et al., 2008) and because of the assumption that existing reference models can be used here. However, while online social reference follows chronologically its predecessor, library reference service (Gazan, 2007, Harper et al., 2008; Shachaf, in press), existing reference frameworks should be used here with great caution. Unlike traditional reference service, social reference is conducted online through a collaborative group effort. As such, social reference may differ significantly from the traditional (and digital) dyadic reference encounter by its social and collaborative nature that involves group effort and open participation. Furthermore, traditional reference research has its limitations also because "a lack of attention [has been] given to theory" in reference research (Saxton \& Richardson, 2002, p.3).

This article aims to provide a framework for online social reference; a framework that combines past reference research with group effectiveness, from a sociotechnical approach. The input-process-output (IPO) framework of social reference that is proposed here addresses the need for a "practical theory" of social reference, "by which reference and information service can be examined and its principles understood..." (Whittaker, 1977, p.57). It is based on an integration of knowledge from library reference research 
(Crews, 1988; Lankes, 2004, 2005; Richardson, 1995, 1999; Saxton \& Richardson, 2002) with IPO models of (virtual and collocated) team effectiveness (Furst, Blackburn, \& Rosen, 1999; Hackman, 1983, 1987; Mathieu, Maynard, Rapp, \& Gilson, 2008; McGrath, 1964). The integration of these models into the social reference IPO model extends reference research and addresses the limited relevance of existing reference models that assume a dyadic interaction and hold a library-centric view of reference services.

\section{Social reference}

Social reference includes question answering services that are provided online by communities of volunteers on Q\&A sites. It does not include fee-based online question answering services (Harper et al., 2008), services in which only a few users can answer (e.g., ChaCha, libraries, AllExpert), or e-services that businesses provide to their own clients. Social reference uses two key features of Web 2.0 (O'Reilly, 2005): wikis (or other Web 2.0 infrastructure) and participation.

Any question that is posted on a Q\&A site is sorted under broad topical categories. Users can answer questions that have been posted and can also categorize and rank questions and answers. When answering a question, users can elaborate, modify, clarify, or contradict previous answers in ways that vary from one site to another. On average, more than two answers are submitted per question by volunteers (Harper et al., 2008; Shachaf, in press); on Yahoo! Answers and on the Wikipedia Reference Desk four or more responses, on average, are submitted per question (Harper et al., 2008; Shachaf, in press). Some of the sites allow users to determine which answer for a given question is the best (e.g., Yahoo! Answers, Askville, and Answerbag. Because some users are more likely to provide better answers, a few Q\&A sites employ a user reputation system (e.g., Yahoo! Answers, Answerbag, and WikiAnswers). Reputation is determined by a set of site-specific criteria; a few highly active users on each of these sites only answer questions and do not ask many (Adamic et al., 2008; Shachaf, in press; Shah et al., 2008; Zhang, Ackerman, Adamic, $\&$ Nam, 2008). Despite the fact that users can participate in various roles (ask, answer, evaluate, and categorize questions) on these sites simultaneously (Bian et al., 2008), only about one fifth of the users participate in dual roles, asking and responding to questions (Adamic et al., 2008; Shachaf, in press).

While social reference and library reference services are engaged in answering users' questions, a major difference between the two is that there is not a "general agreement among librarians that they are in the question answering business" (Durrance, 1995, p.247). In traditional reference, librarians also instruct users, point them in the direction of resources, or walk them over to resources, and only $20 \%$ (Durrance, 1995) to 50\% (Rothstein, 1964) of the time they are engaged in question negotiation and answering. Both social reference and library reference provide services online; still, librarians utilize various synchronous and asynchronous channels for in-person and remote services, whereas social reference is wiki based. Both social reference and library reference assume that collaboration is the norm, but mean different things. Pomerantz (2006, p.46), for example, believes that "as network technology is increasingly utilized... [library] reference work will become fundamentally a collaborative effort," and he argues that the one-on-one interaction 
model that is commonly assumed in library reference is overly simplistic. Still, collaboration in library reference services is mostly at the institutional level, for example through various statewide virtual reference services or (internal or external) referrals, while collaboration in online social reference occurs among individuals also at the level of the individual transaction.

There are additional differences between library reference services and social Q\&A sites. First, in social reference the dyadic reference encounter is replaced by teamwork. Second, the traditional boundaries between patrons and librarians are no longer relevant; boundaries are blurred between users who ask and those who answer, because those who ask may also be those who answer. Third, unlike the library reference services, on some Q\&A sites, a bottom up approach is encouraged to define policies and guidelines; for example, users are empowered and power is decentralized on the Wikipedia Reference Desk. Library administrators, in setting up policies, at best seek user's input into the decision making process while maintaining decision authority. In social reference, user empowerment is achieved in the processes of categorizing, ranking, and answering questions, as well as in evaluating answers. Fourth, unlike traditional reference, which uses institutional human and information resources, social reference relies on volunteers and free online information (Oh et al., 2008; Shachaf, in press).

In sum, the new stage of reference, unlike its predecessors, is characterized by collaborative group work, user empowerment, role ambiguity, use of wikis, volunteers' participation, and the reliance on free information.

\subsection{Q\&A sites as virtual communities}

The social reference encounter takes place within Q\&A sites' context; these sites function as virtual communities (Rheingold, 2000). Social reference can be analyzed at the community level or the transaction level. The distinction between these two levels of analysis resembles the distinction between the group and organization levels of analysis; work groups operate within an organizational context. Likewise, social reference and traditional reference each occur within its own context. Social reference occurs in an online community, and traditional reference encounter takes place in a library. At the transaction level, an ad hoc team of users with a clear task provides an answer to a question; ad hoc teams function within the context of Q\&A sites. Therefore, an understanding of the virtual community and its culture and norms, membership, technological infrastructure, and shared practices are critical contextual variables.

Scholars who focused attention on Q\&A sites, such as Answerbag, Yahoo! Answers, and the Wikipedia Reference Desk, viewed them as online communities (Adamic et al., 2008; Gazan, 2006, 2007 Shachaf, in press). For example, Rafaeli and Ariel (2008, p.257) argued that "Wikipedia defined itself as a community, and special spaces in Wikipedia are dedicated for communal activities. The rhetoric of community is to be found everywhere." They discussed the sense of community in Wikipedia based on research of online groups. Likewise, Gazan (2006, 2007 used the term "community" when discussing Answerbag, which follows the rhetoric of the site itself: "Answerbag is a community of people helping others" (Answerbag, 2009, para. 1).

While social reference may be new in the context of explicit reference services, question answering has a long history in virtual communities and is an integral part of 
their information sharing behaviors. For instance, Burnett and Buerkle (2004)

distinguished between informational and noninformational collaborative behavior and reported that a high percentage of the posts involved queries and answers. This type of information sharing in virtual communities was evident as early as 1985 , with the Experts on Well (an early online community), which was described by Rheingold (2000, p.50): "If you have a problem or a question... you pose it. Then you wait... sometimes nothing happens, and sometimes you get exactly what you want... and the topic serves as a kind of community librarian service that point the query toward the right part of the Well's collection of information."

Information behaviors are rooted within the norms and attitudes of the particular community (Burnett, Besant, \& Chatman, 2001; Burnett, Jaeger, \& Thompson, 2008; Chatman, 1999) and information intermediation, or question answering, is no exception. Both explicit norms (which are codified) and implicit norms (that emerge through the day-to-day interactions) define the acceptable social behaviors in a specific virtual community (Burnett \& Bonnici, 2003). These norms help socialize "newbies" into the community and help the community handle deviant behaviors (Burnett \& Bonnici, 2003; Burnett \& Buerkle, 2004). "Participants [in Answerbag] translate their knowledge, experience and opinions into content that both adheres to and continuously redefines the standards of the community." (Gazan, 2006, p. 73). Burnett, Besant, and Chatman (2001, p.536) suggested that according to the theory of normative behavior, each community "has a specific context that serves a particular population to permit its members to conduct their business in a routine expected manner." Each Q\&A community has its culture and norms of behaviors; these norms govern members' behaviors at the transaction level. Without getting into a discussion about the conceptualization of context in information seeking and sharing literature (Chatman, 1999; Pettigrew, 1999; Savolainen, 2009), I argue that an analysis of social reference encounter should not disregard the context of the virtual community in which it takes place. In each of these Q\&A communities, a set of norms of behaviors will affect members' social and task behaviors. These norms provide "much of the glue that keeps social groups cohesive." (Burnett \& Bonnici, 2003, p. 349).

\subsection{The social reference encounter: Three examples}

Three examples of social reference encounters from the Wikipedia Reference Desk, Yahoo! Answers, and Answerbag are described next. The Appendix includes the full text of these examples. These examples are included only for descriptive purposes to illustrate the collaborative nature of the social reference encounter. Scholars who have been studying these Q\&A sites provide a detailed description of each (Adamic et al., 2008; Gazan, 2006, 2007; Shachaf, in press). A set of behavioral guidelines on each of the Q\&A sites articulate the expected norms of behavior and advise users how to ask and answer questions.

The first example, from the Wikipedia Reference Desk, involves five users who interact with each other in an effort to provide an answer. The users make efforts to clarify and correct each other's errors and thereby improve the answer with each additional post. The group manages conflict (by raising different points of view and making efforts to resolve misunderstandings), builds trust (by sharing information and providing corrections and clarifications), and communicates according to the site's 
culture and norms of behavior (i.e., by signing their posts, avoiding greetings). The user who asked the question posted an unsolicited thank you message, indicating satisfaction with the answer.

The second example, from Yahoo! Answers, involves 46 users. One user asked a question, 19 users answered it, and 26 additional users made comments. The transcript of their communication includes both task and social interaction. Several answers to the question are provided and are evaluated as well as enhanced by other users. Some comments are not task oriented (see for example, comments 35 and 46); these involved conflict (comment 46) as well as trust building and encouragement (comments 22, 32, 36, $38,41,44,45)$. Multiple users express their satisfaction with the process.

The third example, from Answerbag, involves 6 users: one who asked the question and also gave feedback to each of the answers provided by the other five users. By providing feedback, this user increased group cohesion and trust building, and enhanced users' motivation and confidence. This user behaved as a group leader by monitoring and coordinating the group's efforts toward task accomplishment. Here again, the users were engaged in task-related and social interactions. The users adhered to the norms of behavior of this site, by posting answers and comments on the designated areas.

To sum up, conflict management, trust, cohesiveness, motivation, coordination and the maintenance of communication norms are part of the social reference encounter. These social factors should be taken into account in any theoretical framework that seeks to understand, analyze, and evaluate social reference.

\section{Reference research}

Existing reference models can help in the development of a social reference framework because of the similarities between the two types of question answering services. Ranganathan (1931), Rothstein (1964), and Taylor (1968) set the foundations for understanding reference theory and the reference encounter. Whittaker (1977), White (1981, 1985, 1989), Crews (1988), Hernon and McClure (1986), Kulthlu (1988), Durrance (1989), Dewdney and Ross (1994), Richardson (1995, 1999), and Radford (1999) are among those who made major contributions by further developing our understanding of the reference encounter. According to Richardson (1995, pp.89-90), "Much of the literature adopts, either implicitly or explicitly, a system analysis approach or an input-process-output-feedback (IPOF) model... [but] Relatively little attention has been devoted to the activity... that transforms input...into output...."

Three reference models are examined here in light of their potential relevance to online social reference (Crews, 1988; Richardson, 1995, 1999; Saxton \& Richardson, 2002). Each of these three models is briefly described and their possible fit with social reference is considered.

First, the system approach to evaluating reference under the IPO framework, which was developed based on findings from two decades of unobtrusive studies by Crews (1988). His IPO model includes three groups of variables. The first group has the following inputs: type of library, the collection, the library budget, the reference staff, rates of reference use, access, service, and standards, the nature of the patron, the nature of the contact, and the nature of the question. The second group includes process variables: question negotiation, follow-up questions, time allowed for questions, behavior 
of the librarians. Third are the outputs: correct answers, provided within time, and efficient utilization of information resources.

Second, the systems analysis approach to understanding the reference transaction (Richardson, 1999). Richardson $(1995,1999)$ provided a top-level view of the process; he viewed the reference interview and question negotiation as a system that is goal oriented. He identified three events and outlined input and output requirements for each. The first is query negotiation, when the inquirer asks a question (input) and the librarian records and clarifies the question (output). The second event is query resolution, when the inquirer asks a question (input), and the librarian answers with satisfaction or initiates ILL requests and records question types (output). The third event is assessment, when the librarian follows up and receives a response. This model characterizes the reference interview as a process with various stages and a variety of inputs and outputs.

Third, Saxton and Richardson's (2002) most recent and comprehensive work on the reference transaction, and their identification of factors that contribute to high-level reference performance. Saxton and Richardson (2002), partially extending Richardson's (1999) model, suggested that the factors that affect reference success include the query, user, (librarian's) behaviors, librarian, and library (p.11). In their model, performance (accuracy, completeness, usefulness, and user satisfaction) is influenced by five independent variables. These are: (a) query (complexity of the query and the currency of the information being sought); (b) user (education level of the user and the user's familiarity with the library); (c) behavior (service behaviors exhibited by the librarian during the transaction); (d) librarian (education, experience, and job satisfaction of the librarian); and (e) library (size and policies of the library).

These three traditional reference models are beneficial for analyzing and understanding social reference because they view the reference transaction as a system with various input, process and output variables. Saxton and Richardson's (2002) model is the most appealing among the three for use in the context of social reference, partially because it is the most comprehensive (Shachaf \& Horowitz, 2008). It includes both objective outcome measures of accuracy and completeness (Hernon \& McClure, 1986), and subjective measures of user satisfaction (Gross \& Saxton, 2002). The strengths of Saxton and Richardson's (2002) model for understanding social reference also lie in its: (a) performance measures (accuracy and satisfaction); and (b) input and process measures that account for the influence of the inquirer (user), responder (librarian), type and difficulty of the query, and librarian's behavior during the process of question negotiation. Their model was based on an extensive review of the literature and a multivariate empirical examination. These aspects of Saxton and Richardson's (2002) model are used as the building blocks for the social reference framework. Yet, despite the usefulness of Saxton and Richardson's (2002) model to explain social reference, the overall approach has the following limitations:

1. It assumes a dyadic interaction between a librarian and a user while social reference involves participation of multiple users who collaborate at the level of a single transaction. This deficiency is crucial, especially given the fact that boundaries between service providers and consumers are blurred in social reference, and users hold dual roles. A modified framework should integrate the collaborative (virtual) group processes that are part of online social reference. 
2. It does not include the creation and use of an archive of previously answered questions, whereas social reference aims at creating such an archive and participants on Q\&A sites rely heavily on it for processing transactions. These archives of previously asked questions and answers are the cornerstones of Q\&A sites and the driving force of past information retrieval research on the sites. A modified framework for online social reference should take account of such digital repositories.

3. It is library-centric while social reference is user-centric. It emphasizes the role of the library and librarian behavior over that of the user. While it accounts for the effect of the library (policies, collections, and facilities) and librarian's behavior on the outputs, it does not account for the possible effects of user behavior on processes and outputs. A modified framework should incorporate the influence of users' behaviors on outputs as much as it emphasizes the role of the service provider.

4. It assumes that the main form of interaction during the reference encounter is in-person and in real time and does not consider the use of information and communication technology (ICT) during the reference encounter. This is problematic because social reference is conducted online. A modified framework for online social reference should integrate ICT.

It is clear that Saxton and Richardson's (2002) model has integrated assumptions of traditional library reference. It does not capture nor support the fundamental features of online social reference. Among these are: (a) the collaborative and dynamic process of social reference; (b) the user-centric approach where there is an overlap among participants (blurred boundaries between inquirer and responders); (c) the use of ICT; and (d) the creation and utilization of an archive of previously answered questions. These features should be included in an online social reference framework.

\subsection{Digital reference}

With advances in ICT, librarians transformed their reference services to provide services online. The literature about digital reference includes many case studies (e.g., Gilbert, Liu, Matoush, \& Whitlatch, 2006; Ward, 2004, 2005; White, 2001) and practical guidelines (e.g., McClure, Lankes, Gross, \& Choltco-Devlin, 2002). Researchers have addressed the challenges and opportunities that technology-mediated encounters involve (Abels, 1996; Radford, 2006) and focused attention on the creation of an archive of previously asked questions and answers (Lankes, 2004; 2005; Nicholson \& Lankes, 2007). For example, Abels (1996) discusses the e-mail reference interview, Radford (2006 focused on interpersonal communication during the chat-based reference encounter, and Curry (2005) summarized the literature on the reference interview in the electronic setting. Others focused attention on the conceptualization and exploration of digital reference, and while some emphasized the need to develop new frameworks (Lankes, 2004, 2005) and measures for digital reference (Hernon \& Calvert, 2005; McClure, Lankes, Gross, \& Choltco-Devlin, 2002; White, 2001), most "evaluations of virtual reference services utilize similar measures to those of traditional reference" (Shachaf \& Horowitz, 2008, p. 124). Scholars of virtual reference rely heavily on traditional reference research, as they make an effort to understand why and "how digital reference is different from traditional library-based reference research" (Lankes, 2005, p.321-322). 
A few articles proposed frameworks and research agendas and listed open research questions that should be addressed in the study of digital reference (Lankes, 2004, 2005; McClennan \& Memmott, 2001; Pomerantz, 2005; Pomerantz, Nicholson, Belanger, \& Lankes, 2004; White, 2001). Lankes (2004) proposed the most comprehensive framework for analysis of digital reference. He contended (2004, pp.306307): "Two system models have been presented... The first ... seeks to define a digital reference system as a series of roles and the interaction among these roles... [the second is]... modeled as a special case of a complex system."

Lankes $(2004,2005)$ described the impact of information systems through four conceptual lenses that are used for the analysis of digital reference: policy, evaluation, system, and behavior. He integrated technology into the process of question negotiation, as part of the effort to understand the ways in which human expertise can enhance information systems to answer questions. He also integrated the digital archive of questions and answers into his framework. Lankes (2004, 2005), like Richardson (1999), continued the library-centric approach that dominated earlier reference frameworks, and described a Q\&A archive created by experts (librarians) and intended only for experts' use. Unlike in the library-centric approach, in social reference all users (experts and nonexperts) are empowered to create, contribute, and use the archive. In virtual communities, a digital repository of frequently answered questions helps users answer new questions more effectively and efficiently, and more importantly this wiki-based repository also supports social processes (Hansen, Ackerman, Resnick, \& Munson, 2007). Lankes' contribution, however, was to extend reference research into the online environment and to integrate a digital archive of previously answered questions, which are described as part of a system approach to understand technology mediated reference services.

As should be clear, there is a need to modify and strengthen these reference models to social reference. Not only should the social reference framework account for the technological components (both for the mediated communication and for a digital archive of question and answers) and the intertwined relationships between these technologies and their creators and users, but it should also emphasize the collaborative group work that is involved in the process. This latter aspect was missing in all prior conceptualizations of the reference encounter. To address this gap, models of (traditional and virtual) team effectiveness are discussed next.

\section{Team effectiveness}

Models of team effectiveness from small group research are useful for the development of the social reference framework because of the collaborative nature of a typical social reference encounter. Of particular interest are three types of frameworks: (a) self-directed teams (e.g., Cohen, Ledford, \& Spreitzer, 1996), which empower group members; (b) IPO models (e.g., Hackman \& Oldham, 1980; McGrath, 1964) because they share assumptions with existing reference models; and (c) virtual team effectiveness (e.g., Furst et al., 1999; Shachaf \& Hara, 2002) because of the mediated nature of group interaction. Team effectiveness models are examined here in light of their potential to enhance and contribute to the understanding of social reference.

Team effectiveness is a complex construct and the subject of considerable controversy among small group researchers. Many frameworks of team effectiveness 
exist (e.g., Cohen, \& Bailey, 1997; Hackman \& Oldham, 1980; Shea \& Guzzo, 1987; Pearce \& Ravlin, 1987; Sundstrom, DeMuese, \& Futrell, 1990). McGrath (1964,1984), Bettenhausen (1991), Guzzo and Dickson (1996), Cohen and Bailey (1997), Rousseau, Aube and Savoie (2006), and Mathieu, Maynard, Rapp, \& Gilson (2008) reviewed the literature and described relevant frameworks and variables that contribute to team effectiveness. Those relevant for online social reference include self-regulating work groups (Pearce \& Ravlin, 1987) and the self-managing work team model (Cohen, Ledford, \& Spreitzer, 1996) because of the nature of group collaboration that is typical of Q\&A sites. Mathieu et al. (2008) contended that McGrath (1964) IPO model has dominated the research on team effectiveness, and most of the frameworks draw on this model. The IPO model (Mathieu et al., 2008) provides support for most of the process variables, which are largely missing from reference research. "Team processes have played a central role in most, if not all, team effectiveness models ... Team processes ...describe members' interactions directed toward task accomplishment. Processes are important because they describe how team inputs are transformed into outcomes." (Mathieu et al., 2008, p.421).

In social reference, team processes include those required to accomplish the task at hand, which is to answer questions effectively, and for social interaction between team members. It includes, for example, activities such as planning, task accomplishment, coordinating team members, conflict management, and motivation, as well as trust, cohesiveness, and team climate. Processes that involve social interaction among team members have been mostly ignored in reference research; task processes, however, have been incorporated into most reference research models through the extensive discussions that focus on the process of question negotiation and the reference interview. For example, Richardson's (1999) system analysis focuses on task accomplishment processes.

IPO models of team effectiveness are particularly relevant for online social reference because they, like systems models in reference research, have similar assumptions and can be integrated well with and enhance existing reference models. Still, while the IPO models of team effectiveness are useful for understanding group collaboration in social reference, they are limited in that they do not integrate information and communication technology.

With the growth of virtual teams in the workplace, researchers have delineated variables and frameworks for groups in virtual settings (Shachaf, 2008). Some recommend using the same frameworks and performance measures that have been used for traditional face-to-face teams in the context of virtual groups (for example, Furst et al., 1999; Gibson \& Cohen, 2003); others developed new frameworks (Lurey \& Raisingani, 2001; Shachaf \& Hara, 2002); and a few focused on the interplay between ICT and groups (for example, Orlikowski, 1992; DeSanctis \& Poole, 1994, 1997; Kling, McKim, \& King, 2003). Specifically, in the context of social reference, Furst et al.'s (1999) modified normative model (that was based on Hackman's normative [IPO] model of group effectiveness) is appealing because it accounts for the technology and team social processes, and it employs a systems approach. Furst et al.'s (1999) model is helpful for social reference in particular because it addresses two major limitations at once. First, it accounts for the collaborative nature of online social reference processes, as does the IPO model of team effectiveness. Second, it pays attention to the technologies that are 
involved in these processes. Furst et al.'s (1999) model includes organizational context, group design, group synergy, process criteria of effectiveness, material resources, and measures of group effectiveness. This model includes four outputs: "products or services at high standards of quality, quantity, and timeliness... group work processes [that] enhance the capability of the group to work together ... in the future... the group experience [contributes] to the satisfaction and well being of... member[s]..." (p.251); and "the degree to which the team's processes and outputs can be captured electronically, stored and retrieved as needed to contribute to increased levels of organizational knowledge and learning of future teams" (p.253). Their output measures resemble those common in reference research. Performance, satisfaction, and viability match respectively with high quality of service (correct, accurate, timely responses), satisfaction of the user and the librarian, and the user willingness to return to the same librarian (Saxton \& Richardson, 2002). Digital capturing of the process and outputs (Furst et al., 1999) resembles Lankes' (2004) inclusion of a Q\&A archive. In virtual communities, the use of a wiki repository helped participants answer questions more efficiently and effectively; it supported the reuse of information and the peripheral participation by new and former members (Hansen et al., 2007).

To sum up, the IPO models of team effectiveness can enhance existing reference frameworks. By adding team processes, ICT, and additional outcome measures, they address the limitations of reference models in the context of social reference. At the same time, these models fit well with existing reference IPO models because they share similar assumptions of the general system theory (Bertalanffy, 1968).

\section{IPO framework for online social reference}

The input-process-output (IPO) framework integrates reference models (Crews, 1988; Lankes, 2004, 2005; Saxton \& Richardson, 2002) with IPO models of team effectiveness (Furst et al., 1999; Hackman, 1983, 1987; Mathieu et al., 2008; McGrath, 1964, 1984; Shachaf \& Hara, 2002). The general system theory (Bertalanffy, 1968) provides a framework for classifying and evaluating the world and a universal approach to all sciences. The basic components of the system include: inputs, processes, and outputs. Inputs and outputs involve crossing the boundary of the system. Inputs involve resources from the external environment (e.g., information, users, and technology in social reference), and outputs involve resources that the systems generate for the external environment (e.g., answers to questions and an archive of questions and answers in social reference). The process of transforming the inputs into outputs is defined by the systems boundaries (in social reference the process includes questions negotiation through user interactions). The IPO framework is composed of input, process, and output variables (Figure 1); each is described below. 


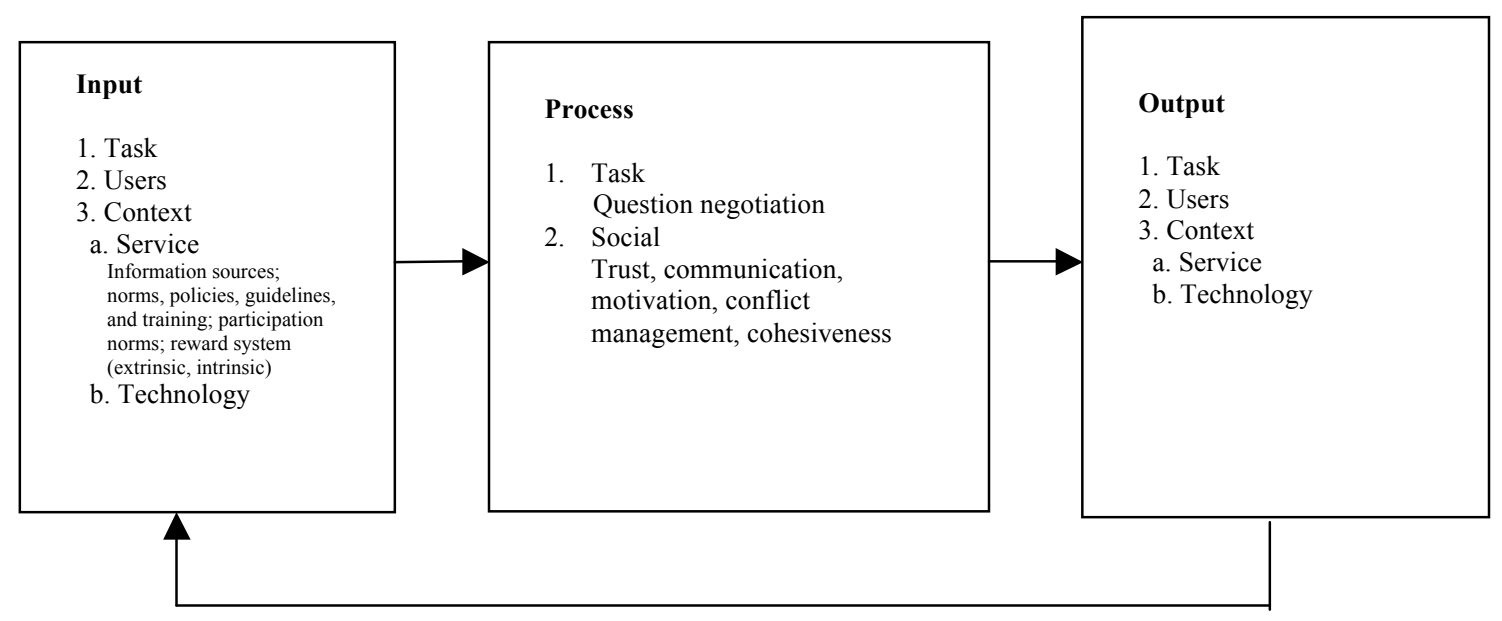

Fig. 1. Input-Process-Output (IPO) model of social reference

\subsection{Inputs}

Input variables involve factors related to the task (question answering), users (demographics, knowledge skills and abilities, roles), and context (information resources, policies, ICT infrastructure). Most of the input variables continue the long tradition of reference research; these have been included in Crews's (1988) model and in Richardson and Saxton's model (2002).

\subsubsection{Task: Question type, difficulty, clarity, and topic}

The social reference framework identifies the query as a critical input that influences processes and outputs (Crews, 1988; Rothstein, 1964; Saxton \& Richardson, 2002). Answering a question successfully depends largely on question type, topic, currency, and clarity (Rothstein, 1964). Rothstein (1964, p.175) divides queries into: "directional... location of a specific book...; ready reference... simple factual answers... standard reference books; search... [or research questions] extended effort... wider use of sources; and readers advisory... choice of book or gathering data." Other classifications include subject, purpose served (school assignment), source (in person, mail, phone), and materials used have been identified (Rothstein, 1964). Rothstein (1964) claims that about $90-95 \%$ of the questions are ready reference and can be answered in 10 minutes or less.

The type of expertise required, the sources that should be consulted, and the currency and depth of the answers expected vary greatly. As a result, the time needed to answer these different questions varies largely. Topical categorization of questions is the norm in most Q\&A sites. Still, it is unclear how these questions resemble or differ from those that are asked at the library reference desk (in-person or online) and how these differences may affect the processes and outcomes of the social reference encounter.

\subsubsection{Users: Participants' knowledge, skills, abilities (KSA); demographics; roles} (askers, responders, evaluators)

Reference models suggest that the users (patrons and librarians) affect the effectiveness of the transaction (Crews 1988; Saxton \& Richardson, 2002). Users bring their own knowledge, skills and abilities (KSA), such as education level and familiarity with the 
subject matter, as well as work experiences, which in turn affect the processes and outputs. Therefore, in addition to the query, demographics such as gender, age, and race, as well as the user's (asker, responders, and evaluators) KSA are included in the IPO model. It is unclear if the impact of these input variables will follow the same patterns that have been observed and documented reference research. Likewise, it is possible that other aspects of KSA will become relevant in this context.

\subsubsection{Context: Service and technology}

1. Service: information sources; norms, policies, guidelines, and training; reward system (extrinsic, intrinsic)

2. Technology: ICT infrastructure

Reference research identified the library context (particularly collections and policies) as influential in the determination of the success of the reference encounter (Crews, 1988; Saxton \& Richardson, 2002). Crews (1988), for example, listed these inputs other than the reference staff: the type of library; the collection; the library budget; the rate of reference use, access, and service; and standards. In order to avoid the library-centric approach, in the social reference framework, the use of general terms replaces the libraryspecific terminology. For example, the term information sources replaces collection; similarly, norms, policies, guidelines, and training, replace the type of library, the library budget, and rate of reference use, access and service, and standards. Both in library reference services as well as on Q\&A sites, the availability of information resources and their ability to be used to find answers for a wide variety of questions will affect the ability of responders to identify accurate and verifiable answers. Likewise, policies and standards of information access and use, available guidelines, and training will all affect service quality, as much as the explicit and implicit Q\&A site's norms (Burnett \& Bonnici, 2003). In addition, (intrinsic and extrinsic) reward systems were added to these input factors; a reward system that addresses a wide variety of users needs (for example, need for affiliation, achievement, recognition, self fulfillment) would influence users' motivation to provide better answers and to continue participation. Raban and Harper (2008, p.73) found "several intrinsic motivations, such as perceived ownership, commitment to a social role and various affective motivations for participation... [in addition to]... a variety of extrinsic factors, including ratings, monetary incentives and social gratification."

ICT infrastructure is included as a contextual variable. This dimension has become an instrumental part in Lankes' (2004) model and is an important component of the social reference framework. Lankes (2004) wrote that an identification of the best information systems is critical for the successful output. He argued: "The concept of 'information system' used in the digital reference definition can be characterized as a special case of a general system [Bertalanffy, 1968] where the input to the system is a user question, the process involves human expertise, and the output is an answer." (p.303) Extending Lankes' (2004) approach, the social reference framework follows a sociotechnical approach (e.g. Kling et al., 2003) that focuses on the mutual shaping between users and ICTs. This attitude toward technology, and ICT in particular, as a contextual variable is common also in small group research (Furst et al., 1999; Mathieu et al., 2008). ICT infrastructure is part of the context and is expected to affect both processes and outputs. It is unclear exactly how ICTs in social reference support 
processes and outputs, but it is clear that variations among Q\&A sites in their ICT infrastructures are likely to be a critical variable to examine.

\subsection{Processes}

Process variables involve activities that on the one hand relate to the task, and on the other hand to activities supporting group maintenance and development, including interactions among individual members of the group. Research on collaborative information sharing in virtual communities distinguishes between task (informational) and social (noninformational and hostile) interactions (Burnett \& Buerkle, 2004). While the first has been addressed in reference research, the latter has been ignored. These group processes include conflict management, cohesiveness, trust building, coordination and leadership, and communicating according to the site's norms of behaviors.

\subsubsection{Task processes}

Task processes include activities such as planning and question negotiation, evaluating questions and answers, and categorizing questions. These have been cornerstones in reference research (e.g., Durrance, 1995; Dewdney \& Ross, 1994; Radford, 1999; Richardson, 1999; Ross, Nilsen \& Dewdney, 2002), and have been examined in the context of digital and virtual reference services (e.g., Abels, 1996; Radford, 2006). Task processes are included in all reference models.

Besides information transfer, interpersonal interaction was recognized as one of the processes that occurs during the reference encounter (e.g., Durrance, 1995; Radford, 1999). The treatment of this encounter in reference research is based on a set of assumptions, including that the reference encounter is a dyadic interaction in which a user asks a question and a librarian answers it, and that a user's satisfaction and willingness to return are the critical outcomes of the reference encounter. The process of question negotiation has been recognized as a communication problem (Radford, 1999), in which both verbal and nonverbal communication affect the encounter. Some authors argue that librarians' interactions with users are comparable to the doctor-patient relationship (e.g., White, 1985), while others advocate the use of counseling techniques (as discussed in Radford, 1999). This approach to the reference encounter has driven the formulation and publication of professional guidelines for librarians (e.g., Ross, Nilsen, \& Dewdney, 2002; Reference and User Services Association [RUSA], 2004); these guidelines are then used for the evaluation of reference transactions (Kwon, 2006; Shachaf \& Horowitz, 2006, 2008; Walter \& Mediavilla, 2005; Ward, 2003; Zhuo, Love, Norwood, \& Massia, 2006).

In social reference, task processes would be valuable predictors of the outputs as much as they have been for the library reference outputs. It is unclear, however, how exactly the question negotiation process is affected when multiple users participate in it in social reference, and how this type of question negotiation, in turn, will affect the transaction's outputs. It would be interesting to examine the differences that result from the increase in number of participants (compared to traditional dyadic encounter) and those that are due to the (various) use of Web 2.0 infrastructure. 


\subsubsection{Group social processes}

Group social processes at the community level on Q\&A sites can be understood based on the knowledge from online communities, but at the transaction level it draws on small group research. The ad hoc teams at the transaction level resemble small groups that function in the context of the virtual community. Social processes involve conflict management, motivation and confidence building, trust, cohesiveness, and team climate and norms (Mathieu et al., 2008). These processes in reference research have been mostly ignored, partially because the reference encounter was not perceived as a group process but as a dyadic encounter with a clear power and role separation between librarians and users.

While prior reference research does not take account of these variables, the three examples that have been described earlier illustrate these processes well (section 3.2 and the Appendix). All three examples exhibit communication patterns that adhere to the various behavioral norms on each Q\&A site. They provide good examples of the importance of trust building (examples 1,2, and 3), conflict management (examples 1 and 2), and team cohesiveness (examples 2 and 3 ). The ability to coordinate and lead the group toward a shared goal is critical; it also plays a role in social reference as has been illustrated in the Answerbag example (example 3).

Drawing on small group research, it is clear that group process affects outcomes (Mathieu et al., 2008), though the nature and the extent that they will affect the output in social reference is unclear. Prior research on virtual teams has shown, for example, that conflict management (Montoya-Weiss, Massey, \& Song, 2001), leadership (Kayworth \& Leidner, 2001), and communication and trust (Jarvenpaa \& Leidner, 1999) influence

team outcomes. The social dynamics among members of ad hoc teams that are formed to solve a question on Q\&A sites may or may not resemble virtual teams, and further understanding of these social processes is much needed.

\subsection{Outputs}

Outputs of online social reference can be assessed by task performance, user satisfaction, service viability, and Q\&A archive as follows:

1. Task: Answer quality (complete, accurate, verifiable, timely, sources used)

2. Users: Satisfaction (askers, responders, evaluators)

3. Context

3.1. Service: Viability through participation, number of users, number of transactions (questions and answers), percent of questions answered

3.2. Technology: Repository of previously answered questions and answers

Saxton and Richardson (2002) propose four performance variables, three of which (accuracy, completeness, and usefulness) are measures of task performance and the fourth is user satisfaction. Hackman suggested that effectiveness is composed of task accomplishment, individuals' satisfaction, and the ability of the group to work together in the future (Mathieu et al., 2008). Furst et al. (1999) added a fourth output, the digital capturing of process and outputs. These frameworks emphasize the importance of both achieving high-quality service as well as meeting the needs of individual group members (satisfaction) and group well-being (viability). 
Drawing on these frameworks, the IPO framework for social reference includes measures at the group (viability), individual (satisfaction), service (task) levels, and technology (previously asked questions and answers). Specifically, it includes (a) answer quality, (b) user satisfaction, (c) service viability, and (d) a digital repository. Answer quality is expressed in terms of whether the response is complete (answers all parts of the question), accurate (correct), verifiable (can be verified by examining reliable external sources), timely (quickly), and useful (Saxton \& Richardson, 2002). The satisfaction of users in various roles should also be considered; this includes the satisfaction of askers, responders, and evaluators. User satisfaction levels based on the outcome (answer, Q\&A archive) or the process (user interaction) may vary; users may be satisfied with the interaction even if the answer is not correct, complete, or useful. As shown in reference research, users and librarians have often evaluated the outcome of the same transactions differently (Saxton and Richardson, 2002): Users have tended to rank their satisfaction higher than the librarians rank their performance, perhaps because they could not easily distinguish between the quality of the information they received and their gratitude toward the service providers. Viability is another outcome measure, and it can be measured through continued participation, users' willingness to return, number of users and percent of returned users, number of transactions (questions and answers), and percentage of questions answered. The ability of various users to continue their participation in Q\&A sites is essential for the viability of the service. Likewise, the creation and use of an archive of Q\&A is essential for answering questions as well as for community maintenance (Hansen et al. 2007).

\section{Conclusion}

Crowd sourcing reference work on social Q\&A sites poses new challenges to reference researchers. New theories and frameworks should be developed or existing models modified to address these challenges, facilitate future research, and enhance our understanding of social reference. Drawing from reference research and small group research, this article extends reference research by adding a much-needed theoretical approach to social reference. It describes a framework for understanding, analyzing, and evaluating social reference. This framework will be useful for researchers of social reference because it provides a clear account of the various components that shape social reference.

Acknowledgement: I wish to thank Blaise Cronin and Howard Rosenbaum for their useful comments and suggestions. 


\section{References}

Abels, E.G. (1996). The e-mail reference interview. Reference Quarterly, 35, 345-358.

Adamic, L.A., Zhang, J., Bakshy, E., \& Ackerman, M.S. (2008). Knowledge sharing and Yahoo! Answers: Everyone knows something. Proceedings of the International World Wide Web Conference. Beijing, ACM.

Agichtein, E., Castillo, C., Donato, D., Gionides, A., \& Mishne, G. (2008). Finding highquality content in social media. Proceedings of Web Search and Web Data Mining. Palo Alto, CA, ACM.

Answerbag (2009). About us. Retrieved July 5, 2009, from http://www.answerbag.com/about/

Bertalanffy, L. (1968). General system theory: Foundations, developments, applications. New York: Braziller.

Bettenhausen, K.L. (1991). Five years of group research: What we have learned and what need to be addressed. Journal of Management, 17, 345-381.

Bian, J., Liu, Y., Agichtein, E., \& Zha, H. (2008). Finding the right facts in the crowd: factoid question answering over social media. Proceedings of the International World Wide Web Conference. Beijing, ACM. (pp. 467-476).

Burnett, G., Besant, M., \& Chatman, E. A. (2001). Small worlds: Normative behavior in virtual communities and feminist bookselling. Journal of the American Society for Information Science and Technology, 52, 536-547.

Burnett, G., \& Bonnici, L. (2003). Beyond the FAQ: Explicit and implicit norms in Usenet newsgroups. Library \& Information Science Research, 25, 333-351.

Burnett, G., \& Buerkle, H. (2004). Information exchange in virtual communities: A comparative study. Journal of Computer Mediated Communication, 9(2). Retrieved July 5, 2009, from http://jcmc.indiana.edu/vol9/issue2/burnett.html.

Burnett, G., Jaeger, P.T., \& Thompson K.M. (2008). Normative behavior and information: The social aspects of information access. Library \& Information Science Research, 30, 56-66.

Chatman, E. A. (1999). A theory of life in the round. Journal of the American Society for Information Science, 50, 207-217.

Cohen, S.G., \& Bailey, D.E. (1997). What makes teams work: Group effectiveness research from the shop floor to the executive suite. Journal of Management, 23(3), 239-291.

Cohen, S.G., Ledford, G.E. Jr., \& Spreitzer, G.M. (1996). A predictive model of selfmanaging work teams effectiveness. Human Relations, 49, 643-676.

Crews, K.D. (1988). The accuracy of reference services: Variables for research and implementation. Library \& Information Science Research, 10, 331-355.

Curry, E.L. (2005). The reference interview revisited: Librarian-patron interaction in the virtual environment. SIMILE: Studies in Media and Information Literacy Education, 5(1), 1-16. 
DeSanctis G., \& Poole, M.S. (1994). Capturing the complexity in advanced technology use: Adaptive structuration theory. Organization Science, 5(2), 121-147.

DeSanctis, G., \& Poole, M.S. (1997). Transition in teamwork in new organizational forms. Advances in Group Processes, 14, 157-176.

Dewdey, P., \& Ross, C.S. (1994). Flying a light aircraft: Reference service evaluation from a user's viewpoint. Reference Quarterly, 34, 217-230.

Dom, B., \& Paranjpe, D. (2008). A Bayesian technique for estimating the credibility of question answerers. Proceedings of the Society for Industrial and Applied Mathematics (SIAM). pp. 399-409. Retrieved August 20, 2008, from http://www.siam.org/proceedings/datamining/2008/dm08_36_Dom.pdf

Durrance, J.C. (1995). Factors that influence reference success: What makes questioners willing to return? Reference Librarian, 49/50, 243-65.

Furst, S., Blackburn, R., \& Rosen, B. (1999). Virtual team effectiveness: A proposed research agenda. Information Systems Journal, 9(4), 249-269.

Gazan, R. (2006, November). Specialists and synthesists in a question answering community. Proceedings of the American Society for Information Science \& Technology Annual Meeting, 43(1), 1-10.

Gazan, R. (2007). Seekers, sloths and social reference: Homework questions submitted to a question-answering community. New Review of Hypermedia \& Multimedia, 13(2), 239-248.

Gibson, C.B., \& Cohen, S.G. (Eds.). (2003). Virtual teams that work: Creating conditions for virtual team effectiveness. San Francisco: Jossey-Bass.

Gilbert, L.M., Liu, M., Matoush, T., \& Whitlatch, J.B. (2006). Digital reference and online instructional services in an integrated public/university library. The Reference Librarian, 46(95-96), 149-172.

Gross, M., \& Saxton, M. L. (2002). Integrating the imposed query into the evaluation of reference service: A dichotomous analysis of user ratings. Library \& Information Science Research, 24, 251-263.

Guzzo, R.A., \& Dickson, M.W. (1996). Teams in organizations: Recent research on performance and effectiveness. Annual Review of Psychology, 47(1), 307-338.

Hackman, J.R. (1983). A normative model of work team effectiveness (Technical Report No. 2). New Haven, CT: Yale School of Organization and Management.

Hackman, J.R. (1987). The design of work teams. In J. Lorsch (Ed.), Handbook of organizational behavior. Englewood Cliffs, NJ: Prentice-Hall.

Hackman, J.R., \& Oldham, G.R. (1980). Work redesign. Reading, MA: Addison-Wesley.

Hansen, D. L., Ackerman, M. S., Resnick, P. J., \& Munson, S. (2007). Virtual community maintenance with a collaborative repository. Proceedings of the 70th Annual Meeting of the American Society for Information Science \& Technology, 44 (1), 1-20.

Harper, F.M., Raban, D., Rafaeli, S., \& Konstan, J.A. (2008). Predictors of answer quality in online Q\&A sites. Proceedings of the Conference on Human Factors in Computing Systems. Florence, ACM. 
Hernon, P., \& Calvert, P. (2005). E-service quality in libraries: Exploring its features and dimensions. Library \& Information Science Research, 27, 377-404.

Hernon, P., \& McClure, C.R. (1986). Unobtrusive reference testing: The 55 percent rule. Library Journal, 111(7), 37-41.

Hitwise (2008, March 19). U.S. visits to question and answer websites increased 118 percent year-over-year. Retrieved November 22, 2008, from http://www.hitwise.com/press-center/hitwiseHS2004/question-and-answerwebsites.php

Jarvenpaa, S.L. , \& Leidner, D.E. (1999). Communication and trust in global virtual teams. Organization Science, 10(6), 791-815.

Kayworth, T.R., \& Leidner, D.E. (2001). Leadership effectiveness in global virtual teams. Journal of Management Information Systems, 18(3), 7-40.

Kling, R., McKim, J., \& King, A. (2003). A bit more to IT: Scholarly communication forums as socio-technical interaction networks. Journal of the American Society for Information Science and Technology, 55(2), 127-148.

Kulthlu, C.C. (1988). Developing a model of the library search process: Cognitive and affective aspects. Reference Quarterly, 28, 231-242.

Kwon, N. (2006). User satisfaction with referrals at a collaborative virtual reference service. Information Research, 11(2). Retrieved January 15, 2009, from http://informationr.net/ir/11-2/paper246.html

Lankes, R.D. (2004). The digital reference research agenda. Journal of the American Society for Information Science and Technology, 55(4), 301-311.

Lankes, R.D. (2005). Digital reference research: Fusing research and practice. Reference \& User Services Quarterly, 44(4), 320-326.

Lurey, J.M., \& Raisinghani, M.S. (2001). An empirical study of best practices in virtual teams. Information \& Management, 38, 523-544.

Mathieu, J., Maynard, M.T., Rapp, T., \& Gilson, L. (2008). Team effectiveness 19972007: A review of recent advancements and a glimpse into the future. Journal of Management, 34(3), 410-476.

McClennen, M., \& Memmott, P. (2001). Roles in digital reference. Information Technology and Libraries, 20(3), 143-148.

McClure, C.R., Lankes, R.D., Gross, M., \& Choltco-Devlin, B. (2002). Statistics, measures and quality standards for assessing digital reference library services: Guidelines and procedures. Syracuse, NY: Information Institute of Syracuse. Retrieved December 27, 2008, from: http:/quartz.syr.edu/quality/Quality.pdf

McGrath, J.E. (1984). Groups: Interaction and performance. Englewood Cliffs, NJ: Prentice-Hall.

McGrath, J.E. (1964). Social psychology: A brief introduction. New York: Holt, Rinehart, and Winston.

Montoya-Weiss, M.M., Massey, A.P., \& Song, M. (2001). Getting it together: Temporal coordination and conflict management in global virtual teams. Academy of Management Journal, 44(6),1251-1262. 
Nicholson, S., \& Lankes, R.D. (2007). The Digital Reference Electronic Warehouse (DREW) Project: Creating the infrastructure for digital reference research through a multi-disciplinary knowledge base. Reference and User Services Quarterly, 46 (3), 45-59.

Oh, S., Oh, J.S., \& Shah, C. (2008). The use of information sources by Internet users in answering questions. Proceedings of the Annual meeting of the American Society for Information Science and Technology, 45(1), 1-13.

O’Neill, N. (2007). Chacha, Yahoo!, and Amazon. Searcher, 15(4), 7-11.

O’Reilly, T. (2005). What is Web 2.0. Retrieved January 9, 2009, from http://www.oreillynet.com/pub/a/oreilly/tim/news/2005/09/30/what-is-web-20.html

Orlikowski, W.J. (1992). The duality of technology: Rethinking the concept of technology in organizations. Organization Science, 3, 398-427.

Pearce, J.A.I., \& Ravlin, E.C. (1987). The design and activation of self-regulating work groups. Human Relations, 40, 751-760.

Pettigrew, KE. (1999). Waiting for chiropody: Contextual results from an ethnographic study of the information behaviour among attendees at community clinics. Information Processing \& Management, 35(6), 801-817.

Pomerantz, J. (2005). A conceptual framework and open research questions for chatbased reference service. Journal of the American Society of Information Science and Technology, 56(12), 1288-1302.

Pomerantz, J. (2006). Collaboration as the norm in reference work. Reference \& User Services Quarterly, 46(1), 45-55.

Pomerantz, J., Nicholson, S., Belanger, Y., \& Lankes, R.D. (2004). The current state of digital reference: Validation of a general digital reference model through a survey of digital reference services. Information Processing \& Management, 40(2), 347-363.

Raban, D. \& Harper, M. (2008). Motivations for answering questions online. In D. Caspi, D., \& T. Azran (Eds.), New media and innovative technologies. Beer Sheva, Israel: Ben-Gurion University Press, Tzivonim Publications. pp.73-97. Retrieved July 5, 2009 from http://cmsprod.bgu.ac.il/NR/rdonlyres/34396BDB-6C0E-4931-A077697451885123/38249/MicrosoftWordraban.pdf

Radford, M.L. (1999). The reference encounter: Interpersonal communication in the academic library. Chicago: Association of College and Research Libraries.

Radford, M.L. (2006). Encountering virtual users: A qualitative investigation of interpersonal communication in chat reference. Journal of the American Society for Information Science and Technology, 57(8), 1046-1059.

Rafaeli, S., \& Ariel, Y. (2008). Online motivational factors: Incentives for participation and contribution in Wikipedia. In A. Barak (Ed.), Psychological aspects of cyberspace: Theory, research, applications (pp. 243-267). Cambridge, UK: Cambridge University Press.

Ranganathan, S.R. (1931). The five laws of library science. London: Edward Goldston. 
Reference and User Services Association (2004). Guidelines for behavioral performance of reference and information service providers. Retrieved December 5, 2008 from http://www.ala.org/ala/rusa/rusaprotools/referenceguide/guidelinesbehavioral.htm

Rheingold, H. (2000). The virtual community: Homesteading on the electronic frontier. Cambridge, MA: MIT Press.

Richardson, J.V. (1995). Knowledge-based systems for general reference work: Applications, problems, and progress. San Diego: Academic Press.

Richardson, J.V. (1999). Understanding the reference transaction: A systems analysis perspective. College \& Research Libraries, 60(3), 211-222.

Ross, C.D., Nilsen, K., \& Dewdney, P. (2002). Conducting the reference interview. New York: Neal-Schuman Publishers, Inc.

Rothstein, S. (1964). The measurement and evaluation of reference service. Library Trends, 12(3), 456-472

Rousseau, V., Aube, C., \& Savoie, A. (2006). Teamwork behaviors: A review and an integration of frameworks. Small Group Research, 37, 540-570.

Savolainen, R. (2009). Small world and information grounds as contexts of information seeking and sharing. Library \& Information Science Research, 31, 38-45.

Saxton, M.L., \& Richardson, J.V. (2002). Understanding reference transactions: Transforming an art into a science. San Diego: Academic Press.

Shachaf, P. (2008). Cultural diversity and information and communication technology impacts on global virtual teams: An exploratory study. Information and Management, 45(2), 131-142.

Shachaf, P. (in press). The paradox of expertise: Is the Wikipedia Reference Desk as good as your library? Journal of Documentation, 54. Retrieved December 6, 2008, from http://ella.slis.indiana.edu/ shachaf/paradox.pdf

Shachaf, P., \& Hara, N. (2002). Ecological approach to virtual team effectiveness. Proceedings of Americas Conference on Information Systems, 8, 1814-1819. AIS.

Shachaf, P., \& Horowitz, S. (2006). Are virtual reference services color blind? Library \& Information Science Research, 28, 501-520.

Shachaf, P. \& Horowitz, S. (2008). Virtual reference service evaluation: Adherence to RUSA behavioral guidelines and IFLA digital reference guidelines. Library \& Information Science Research, 30, 122-137.

Shah, C., Oh, J.S., \& Oh, S. (2008). Exploring characteristics and effects of user participation in online social Q\&A sites. First Monday, 13(9), retrieved September 29,2008 , from

http://firstmonday.org/htbin/cgiwrap/bin/ojs/index.php/fm/article/viewArticle/2182/2 028

Shea, G.P., \& Guzzo R.A. (1987). Groups as human resources. Research in Personnel and Human Resources Management, 5, 323-356.

Shirky, C. (2008). Here comes everybody: The power of organizing without organizations. New York: Penguin Books. 
Sundstrom, E., DeMuese, K.P., \& Futrell D. (1990). Work teams: Applications and effectiveness. The American Psychologist, 45(2), 120-133.

Surowiecki, J. (2004). The wisdom of crowds. New York: Anchor Books.

Taylor, R.S. (1968). Question negotiation and information seeking in libraries. College and Research Libraries, 29(6), 178-194.

Walter, V.A., \& Mediavilla, C. (2005). Teens are from Neptune, librarians are from Pluto: An analysis of online reference transactions. Library Trends, 54(2), 209-227.

Ward, D. (2004). Measuring the completeness of reference transactions in online chats; Results of an unobtrusive study. Reference and User Services Quarterly, 44(1), 4658.

Ward, D. (2005). Why users choose chat? A survey of behavior and motivations. Internet Reference Services Quarterly, 10(1), 29-46.

Weinberger, D. (2007). Everything is miscellaneous: The power of the new digital disorder. New York: Henry Holt \& Co.

Whittaker, K. (1977). Towards a theory for reference and information service. Journal of Librarianship and Information Science, 9(1), 49-63.

White, M.D. (1981). Dimensions of the reference interview. Reference Quarterly, 20(4), 373-381.

White, M.D. (1985). Evaluation of the reference interview. Reference Quarterly, 25(1), $76-84$

White, M.D. (1989). Different approaches to the reference interview. The Reference Librarian, 25, 631-646.

White, M.D. (2001). Digital reference services: Framework for analysis and evaluation. Library \& Information Science Research, 23, 211-231.

Zhang, J., Ackerman, M.S., Adamic, L., \& Nam, K.K. (2007). QuME: A mechanism to support expertise finding in online help-seeking communities. Proceedings of the $20^{\text {th }}$ Annual ACM Symposium on User Interface Software and Technology. Newport, RI, ACM.

Zhuo F., Love, M., Norwood, S., \& Massia, K. (2006). Applying RUSA guidelines in the analysis of chat reference transcripts. College \& Undergraduate Libraries, 13(1), $75-$ 88. 
Appendix

\section{Examples of reference transactions}

\section{Example 1: The Wikipedia Reference Desk}

>>USER 1: Is it possible to find out the breakdown of the nationalities of all the editors that edit the English Wikipedia?

>>USER 2 [3 minutes after first post]: No. The best you can do is find out the location of the IP addresses people edit from, which data is gathered at meta:Edits by project and country of origin [provide link].

>>USER 1 [6 minutes after first post]: Thanks for swift reply.

>>USER 3 [12 minutes after first post]: Also see Category: Wikipedians by ethnicity and nationality [provide link].

>>USER 4 [1 hour and 42 minutes after first post]: Though note that the data from that category means nothing. Most Wikipedians don't add themselves to such categories, so the category itself has little meaning as to the overall breakdown.

>>USER 3 [4 hour and 39 minutes after first post]: I'm sorry if you took my comment to mean that it would provide accurate data for all Wikipedians. There are only $\sim 130$ Wikipedians in that cat.

>>USER 4 [14 hour and 01 minutes after first post]: Definitely more then 130. I think you're confused by the subcat figure

>>USER 5 [22 hour and 17 minutes after first post]: I'm sure I remember seeing a pie chart of editors by nationality somewhere around, though I can't think where that might have been, especially as it has little relevence to anything I remember looking at on here recently. 


\section{Example 2: Yahoo! Answers}

>>USER 0: Where did the term "roger" (for pilots) originate?

>>USER 1[Best Answer - Chosen by Asker]: Roger is a word used in one prominent radio alphabet to stand for the letter $\mathrm{R}$. These alphabets use words to represent letters; such alphabets are known as "radio alphabets" or "phonetic alphabets," among other names, and are used for many different languages. The alphabet in which Roger stands for R begins "Able Baker Charlie Dog...," and was the official radio alphabet of the U.S. Navy before 1954. Another familiar alphabet, the NATO phonetic alphabet, which is used by the International Civil Aviation Organization and the Federal Aviation Administration, begins "Alpha Bravo Charlie Delta"; this alphabet uses Romeo for R. There is a page devoted to these alphabets here.

The $\mathrm{R}$ that Roger is substituting for stands for received, indicating that a radio message has been received and understood. The use of radio-alphabet terms to stand for other words is common in the military; roger is a well-known example, and another example is Charlie referring to Viet Cong troops, which comes from Victor Charlie, a radio-alphabet spelling of VC for Viet Cong.

Wilco is not from a radio alphabet; it's a military abbreviation for will comply, indicating that a message that has been received will be complied with. It's necessary to acknowledge receipt of a message with Roger before indicating compliance with wilco, hence the frequent combination Roger, wilco.

Both Roger in this sense and wilco appear for the first time during World War II

Source(s):

http://www.randomhouse.com

$>>$ USER 0: Nice.

>>USER 2: "roger" is the spoken word for the letter " $\mathrm{R}$ "; roger is used to mean

"received".

Roger $=\mathrm{R}$

Alpha $=$ A

>>USER 3: The word "Roger" is a term meaning "message received and understood" used in radio communications. The letter R - the initial of "Received" in the phonetic alphabet used to be "Roger". In 1956 the NATO alphabet was adopted and the initial R was now phonetically called "Romeo". However, the word Roger had becoome so well known and widely used that its use for "received" stuck.

>>USER 4: The word is used in radio communications to indicate receipt of a message. From around 1938 it was the military phonetic for the letter "R" abbreviation for "Received," later replaced by "Romeo."

In the old days of radio when Morse code was still used, radiomen used the letter "R", dot dash dot (di-dah-dit) as a quick way to transmit acknowledgement of transmissions or as a "yes." When voice radiotelephony was developed, the old radiomen stuck to the " $\mathrm{R}$ " as meaning yes. Since the phonetic alphabet for " $R$ " then was Roger, the carryover was a natural logical development.

It is still used today in military parlance to acknowledge the receipt of a command or orders, i.e. "Roger, returning to base" or "Roger, Wilco." With the widespread use of cell phones and SMS (short messaging services) or "text" messaging, Roger is slowly being replaced by " $\mathrm{K}$ " for OK outside of military use. 
Source(s): http://en.wikipedia.org/wiki/Roger

>>USER 5: the usage of the term "roger" dates back to the World War 2

...it stands for the letter " $R$ " in the phonetic alphabet...it was an abbreviation for

"RECEIVED" and eventually bcame radiospeaks as "OK" or "I UNDERSTAND"...c"on man...check the link out...i ${ }^{i} \mathrm{~m}$ tired in typing $\mathrm{u}$ know...[wink][wink]

Source(s): http://www.wordorigins.org/wordorr.htm

>>USER 6: ROGER, in the meaning of "Yes, O.K., I understand you," is voice code for the letter R. It is part of the "Able, Baker, Charlie" code known and used by all radiophone operators in the services. From the earliest days of wireless communication, the Morse code letter R (dit-dah-dit) has been used to indicate "OK-understood." So "Roger" was the logical voice-phone equivalent.

Source(s):http://www.phrases.org.uk/bulletin_board...

>>USER 7: Incidentally according to the "Morris Dictionary of Word and Phrase

Origins" by William and Mary Morris(Harper Collins, New York, 1977, 1988). ROGER

-- "in the meaning of 'Yes, O.K., I understand you -- is voice code for the letter R. It is

part of the 'Able, Baker, Charlie' code known and used by all radiophone operators in the services in the 40 's -50 's.

From the earliest days of wireless communication, the Morse code letter R (dit-dah-dit) has been used to indicate 'O.K. -- understood.' So 'Roger' was the logical voice-phone equivalent." Also from "I Hear America Talking" by Stuart Berg Flexner (Von Nostrand Reinhold Co., New York, 1976)."Roger! A code word used by pilots to mean 'your message received and understood' in response to radio communications; later it came into general use to mean 'all right, OK.' Roger was the radio communications morse code word for the letter R, which in this case represented the word 'received.' 'Roger Wilco' was the reply to 'Roger' from the original transmitter of the radio message, meaning 'I have received your message that you have received my message and am signing off." Wilco implies "I will comply"

Source(s): ORIGIN OF HAM SPEAK - FACT, LEGENDS AND MYTHS???

Compiled By AC6V From The Internet and Other Unreliable Sources

>>USER 8: [>>USER 3] has the best answer, so I will not add further except to say that in addition to a word indicating the affirmative, Roger has evolved into a verb.

>>USER 9: Most definitely from the movie "Airplane" with Leslie Nielsen.

>>USER 10: morse code for affirmative was an " $r$ "

$\mathrm{R}$ in phonetic alphabet $(\mathrm{a}=\mathrm{alpha} \mathrm{b}=$ bravo) was roger

>>USER 11: Ask Yahoo! had a great description of why "roger" means "OK." http://ask.yahoo.com/ask/20030811.html

>>USER 12: When you say roger it's as if you 're saying "come over" while your two fingers are in your mouth... Isn't it roger relatively means come over? It's just a wild guess...

>>USER 13: I believe I read something about that and it said that the first guy who said it was talking to a guy named Roger.

$>>$ USER 14: a guy named roger was flying the plane?

$>>$ USER 15: Naval based

>>USER 16: when graham bell invented telephone......arter they said hello....they said

roger please bring me my wine... and roger replied.roger...thats it/....

>>USER 17: Thank you for this question. I learned something new today. 
>>USER 18: the airplane movie

>>USER 19: Maybe it was a gay pilot calling his boyfriend. "Roger! Roger! Where are you".

\section{Comments:}

>>USER 21:Just an added note, Roger and Wilco are not used together in the Military Affiliate Radio System. Not sure about other services.

>>USER 22: I really enjoyed all this radio-military information. Thanks. Jimmy

$>$ >USER 23: Actually, the U.S. Army's current common task training manual says

"roger, wilco" is kind of redundant, and not proper usage. In the military, if you've acknowledged receiving of an order, it's assumed you will comply with it.

$>>$ USER 24: Roger isn't recognized in the official nato alphabet. Romeo is the correct word for "R."

$>>$ USER 25: my weeiner is on fire@!!!!!!!!!!!!!

>>USER 26: "Roger" is not the phonetic alphabet equivalent for the letter " $R$ " - that would be "Romeo" which is easier to distinguish because of its multi-syllable sound. We ham radio operators still use the phonetic alphabet so that we may be more easily understood despite static or other background noise.

>>USER 27: I've got the whole aviation alphabet

Alpha, Bravo, Charlie, Delta, Echo, Foxtrot, Golf, Hotel, India, Juliette, Kilo, Lima, Mike, November, Oscar, Papa, Quebec, Romeo, Sierra, Tango, Uniform, Victor, Whiskey, X-ray, Yankee, and Zulu.

>>USER 28: And, also, pilot say 'niner' for nine, because nine comes out of the radio as five.

$>>$ USER 29: Roger means in short of "i understand that or i understand"

$>>$ USER 30: or like do you u copy? roger that sir or madam

$>>$ USER 31: What does 10-4 mean on walkie-talkies?

>>USER 32: I would have given this rating a 5 star for effort and structure! Really enjoyed and appreciated information. Thanks.

>>USER 33: To the person who asked what 10-4 means:

It's basically the same thing as "Roger" it means "Ok" or "I understand"

>>USER 34: roger is like got you like $i$ heard wait $u$ said informing the person they $r$ talking to that they under stand them

>>USER 35: why do u help ppl u do not even know and waste ur time

for ONLY 2 points??????

>>USER 36: Good answer!

>>USER 37: As several said, the phonetic "roger" has it's roots in morse code where letters are used in place of common words or phrases to speed communications. The letter " $r$ " was once used to signify "message received." With voice, those same operators engage similar practices, using phonetics. - W5NET

>>USER 38: well this information is very understandeble got to say this on

spanish......que buena respuesta.......jaimejr72@yah...

>>USER 39: teknicly "roger" means that thay heard your last transmishin

>>USER 40: Roger That. (or just Roger) is used in tac-com for ground forces in any U.S. Armed Forces it means $u$ have heard AND understood the last transmission, HUA? 
>>USER 41: The best answer is an excellent answer and I give it 5 stars. This is a fascinating subject.

>>USER 42: long winded answer for avaition copy for $r$ is for roger tor is for romeo...sigh.Roger is very much discouraged in today's commercial military pilot by FAA.

>>USER 43: To those who are saying "Actually, Roger is not the correct phonetic word for R" you are right, but noone said it was now, if you read his answer he clearly states that Roger was the correct phonetic word for the letter R prior to 1954.

$>>$ USER 44: I found this answer to be very informative.

>>USER 45: Nice response. Your Randomhouse.com link wasn't too helpful though. >>USER 46: why do you idiots all keep repeating the same crap you read off some internet site, the question was answered already, theres no need to keep saying the same $* * * *$ over again, idiots 


\section{Example 3: Answerbag}

>>USER 1 [10:49]: In Greek mythology, what was the labyrinth?

> USER 2 [Top answer - 2 hours and 19 minutes after first post]: Labyrinth

The labyrinth is an ancient meditative art form whose design can serve as a metaphor of one's life journey. Its path helps walkers circle inward to the center of their soul. The labyrinth's center represents moving toward a goal and allowing one to release emotions that they carried inside - in order to create or envision a solution as one turns around in order to work one's way back. This liberating exercise lifts us out of our linear, left-brain thought processes by joyfully invoking our intuitive, creative right brain.

During various time periods of its 4,000-year existence, religions throughout the world have embraced its mysterious healing abilities. Labyrinths are typically found in cathedrals, hospitals, parks and residences.

Some walk the labyrinth methodically, heel-to-toe, as a contemplative and joyful pilgrimage to draw in, closer to God. Others tread fearfully on their knees, as a penitence for sin.

There are two basic types of labyrinths: the Cretan and the Chartres.

The Cretan labyrinth is named after the island of Crete and takes the walker into seven arc circuits in which the center is a cross.

The Chartres is named after the stone labyrinth in the floor of the Chartres Cathedral in France. It carries the walker through eleven paths that wind through four quadrants of a circle. It also has a cross in the layout with a rosette in the center which is said to represent the Virgin Mary.

Prayerfully, meditatively walking a labyrinth can help deepen your spirituality, no matter which path you choose.

http://www.aiht.edu/doorways/labyrinth_door.asp

Comments

>>USER 1 [ 5 hours and 41 minutes after firs post]: Very cool, but that's not the answer. Hint: Greek mythology.

>>USER 2 [6 hours and 47 minutes after first post]: I always thought a labyrinth was a maze.

>>USER 2 [6 hours and 52 minutes after first post]: OK, my mistake. I just corrected myself. Check out \#3 of 5 and let me know if that's it. :-))

>>USER 3 [6 hours and 24 minutes after first post]: My mythology is a bit rusty, but: A labyrinth was a large maze type thing that contained a monster called a Minotaur. The minotaur was in the center of the labyrinth and was deadly.

Comments

>>USER 1 [16 hours and 47 minutes after first post]: Excellent

>>USER 3 [19 hours and 58 minutes after first post]: Thanks!

>>USER 4 [2 minutes after first post]: Yeah, it was a huge maze, but what was the monster?? Was it the Chimaera?

Comments

>>USER 1 [16 hours and 49 minutes after first post]: Perhaps you can read the other 
answers.

>>USER 5 [2 minutes after first post]: it was half man and half bull thats all $\mathrm{i}$ know. chimera does sound familioar though

Comments

>>USER 1 [14 minutes after firs post]: I think your thinking of the Minotaur.

>>USER 6 [1 minute after first post]: The labryinth was the maze that the bull thing monster was in. they took people as sacrafices and tied string to find their way or something

Comments

>>USER 1 [16 hours and 49 minutes after first post]: Thanks.

>>USER 2 [6 hours and 20 minutes after first pos]: Labyrinth (LAB-i-rinth). A fiendishly intricate maze devised by Daedalus to house the Minotaur. The myth of an impossibly complex series of corridors may have been inspired by travelers' tales of the historical palace or temple compound of Knossos.

The name "Labyrinth" comes from the word "labrys" meaning "double-ax", and the dynasty of King Minos was referred to as the "House of the Double-Ax". Clearly there is history behind the myth here, for many images of double-axes have been found by archaeologists on Crete from a time even earlier than that of the mythological heroes. But such images are far older still, being found on European icons from as long ago as 5000 B.C.E. And before they became stylized as double-headed axes with curved blades, it is clear that they depicted butterflies. Because of its transformation from a caterpillar, the butterfly represented change and rebirth to the people of the Stone Age, and therefore it was revered as a form of the Great Goddess.

Other images of the Great Goddess in the form of a snake are characteristic of the Minoan civilization. Snakes were sacred symbols because they shed their skin and were in that sense reborn, and the rebirth of the crops and edible plants in the springtime was humankind's greatest preoccupation. So a snake might be worshipped or serve a ceremonial role, either as a symbol or an embodiment of the Goddess herself. Crete was last outpost of female-oriented religion and the point of contact between prehistoric Europe and the world of the ancient Greeks. Minoan Crete is a window through which we can look back at the spiritual roots of Europe. According to the myths, Zeus was born on Crete or sheltered there in a cave on Mount Dicte. Thus the Greeks acknowledged a more ancient spiritual heritage

Comments

>>USER 1 [16 hours and 49 minutes after first post]: Got it. + on your first answer. 